\title{
28 Research Square \\ The Top 5 Causes of Death In China From 2000 To 2017
}

Haiyin Zou

Huanghuai University

Xinjie Tian

Zhengzhou University

Yongcheng Ren ( $\nabla$ ryc12@sina.com )

Huanghuai University

\section{Research Article}

Keywords: secular trend, causes of death, public health

Posted Date: January 3rd, 2022

DOI: https://doi.org/10.21203/rs.3.rs-1198107/v1

License: (c) (i) This work is licensed under a Creative Commons Attribution 4.0 International License.

Read Full License 


\section{Abstract}

Background: Limited information is available on the epidemiological characteristics of major causes of death in the last 18 years. In this study, we investigated the epidemiological characteristics of the top 5 causes of death in China from 2000 to 2017.

Methods: Data were obtained from the 18-year reports of Ministry of Health and analyzed by Grid Search Method, Permutation test, and log-linear regression model.

Results: The top 5 consistent causes of death, malignant tumor, cerebrovascular disease, heart trouble, respiratory disease, trauma and toxicosis accounted for $82.6 \%$ in $2000,86.49 \%$ in 2017 in urban areas and $83.31 \%$ in $2000,88.34 \%$ in 2017 in rural areas. The increasing trends $(P<0.05)$ of proportions of death of malignant tumor, cerebrovascular disease, and heart trouble have average annual percent change $(\mathrm{AAPC})=0.5 \%, 0.3 \%, 2.4 \%$ in urban areas and $1.7 \%, 1.5 \%, 4.3 \%$ in rural areas. The AAPCs of respiratory disease are $-1.4 \%$ in urban areas and $-3.6 \%$ in rural areas. Cardio-cerebrovascular disease increased (Urban: $39.02 \%$ to $43.56 \%$, AAPC $=1.3 \%, P<0.05$; Rural: $32.03 \%$ to $45.91 \%$, AAPC $=2.7 \%, P<0.05$ ) steeply from 2000 to 2017 which are higher than that of malignant tumor $(P<0.05)$.

Conclusion: The top 5 causes of death in China accounted for more than $85 \%$ of all deaths in 2017 , in which cardio-cerebrovascular disease accounted for the largest proportion with the steepest increasing trend.

\section{Introduction}

One of the most important ways to assess the effectiveness of a country's health system is to measure the number of deaths and their causes each year ${ }^{1}$. It is also important to understand the way how diseases and injuries affect people. Health authorities could use the statistics data of different causes of death during different periods as an effective tool to establish their focus in public heath area which may help both to extend the lifespan and to improve the life quality of their people ${ }^{1}$.

The noncommunicable diseases caused by aging and health transitions have brought huge burden to the developing countries, increasing the most economically productive age span rapidly in those countries. Therefore, to developing countries, adult mortality rate becomes an important indicator for a comprehensive assessment of the mortality pattern in the population ${ }^{2}$. It is critical to improve the quality of cause-of-death data to improve the health conditions and reduce preventable deaths in population of the developing countries. In 1987, Ministry of Health of China established a vital registration system to record the incidence and causes of death. Until 2005, this system had covered 41 urban sites and 85 rural sites with population from 30,000-70,000 3,4 . From 2006 to the present, the cause-of-death monitoring system which includes 161 monitoring sites, has been carried out on the National Disease Surveillance System ${ }^{4}$. Our study analyzed the nationally representative data provided by the Ministry of Health and 
explored the epidemiological characteristics and secular trends of the top 5 causes of death in China from 2000 to 2017, trying to find the focus of intervention to reduce the risk of death.

\section{Methods}

\section{Study design and sample}

In this study, data of the proportion and causes of death were obtained from the China Statistical Yearbooks (2001-2018) ${ }^{5}$, which have been provided by the Ministry of Health and published by national bureau of statistics of China annually since 2001. The original sample was collected by using multistage stratified and cluster probability proportional sampling methods, which consists of participants from the general population of China with the provincial units as a secondary population, but excludes the population of Hong Kong, Macao and Taiwan. Data of diseases were classified based on the International Classification of Diseases (ICD-10). The specific ICD-10 code varies for each aggregated cause of death which follows the description in the Disease Classification and Code (GB/T14396-2001), issued by the Ministry of Health.

\section{Statistical analysis}

Grid Search Method and Permutation test were used to find the joinpoints ${ }^{6}$. The log-linear regression model was used to calculate the estimated annual percent change (APC) and average annual percent change (AAPC). The AAPC is equal to the APC of a segment, if the AAPC lies entirely within a single joinpoint segment. The APC confidence interval is based on a t-distribution. The corresponding data for the AAPC is based on the normal distribution, if the AAPC is within one segment, the t-distribution is used. Data are presented on percentages. Statistics analysis was conducted by using Joinpoint Regression Program 4.7.0.0 (Statistical Research and Applications Branch, National Cancer Institute). $P<0.05$ (twosided) is considered statistically significant.

\section{Results}

The top 5 consistent causes of death are malignant tumor, cerebrovascular disease, heart trouble, respiratory disease, and trauma and toxicosis, of the period from 2000 to 2017. These 5 diseases account for $82.6 \%$ in $2000,86.49 \%$ in 2017 in urban areas and $83.31 \%$ in $2000,88.34 \%$ in 2017 in rural areas of the total deaths, respectively. The corresponding data were $83.99 \%, 87.15 \%, 83.40 \%$, and $88.93 \%$ in males and $80.90 \%, 85.59 \%, 81.63 \%$, and $87.51 \%$ in females. In urban areas, the first cause of death is malignant tumor continuously, while cerebrovascular disease and heart trouble flip in the second and third places, from 2000 to 2017. In 2000 and 2001, the first cause of death in rural areas, is respiratory disease, which drops to the third in 2002, and has dropped to the fourth by 2009 , being replaced by heart trouble. After 2009, the top 3 consistent causes of death in rural areas are malignant tumor, cerebrovascular disease and heart trouble. Trauma and toxicosis is the fifth top cause of deaths in both 
females and males continuously, and it accounts for a higher proportion of death in males than in females $(P<0.05)$, especially in rural areas.

In urban areas (Table 1, Online Supplementary Figure s1), trend analysis based on joinpoint regression program shows that the AAPC of malignant tumor, heart trouble, and respiratory disease are $0.5 \%, 2.4 \%$, and $-1.4 \%$ from 2000 to 2017 , respectively $(P<0.05)$. The proportion of deaths caused by malignant tumor has an increasing trend from 2000 to 2008, and its APC $=1.7 \%(P<0.05)$ (Online Supplementary Figure s1A3). However, the trend is not significant from 2008 to 2017 ( $P>0.05)$. The proportions of deaths caused by cerebrovascular disease and heart trouble increase with APC $=0.7 \%$ and APC $=2.9 \%$ (Online

Supplementary Figure s1-B3, C3), respectively $(P<0.05)$, from 2002 to 2017 . Stratification analysis by gender reveals that the proportion of deaths caused by trauma and toxicosis from 2000 to 2017 has a declining trend with AAPC $=-1.1 \%(P<0.05)$ in females, while the trend is not significant in males. 
Table 1

The trends of the top 5 causes of death in urban areas of China from 2000 to 2017

\begin{tabular}{|c|c|c|c|c|c|c|}
\hline \multirow[t]{2}{*}{ Gender } & \multirow[t]{2}{*}{ Diseases } & \multicolumn{2}{|l|}{ Trends (1) } & \multicolumn{2}{|l|}{ Trends (2) } & \multirow{2}{*}{$\begin{array}{l}\text { AAPC } \\
(95 \% \mathrm{Cl}, \\
\%)\end{array}$} \\
\hline & & Year-range & $\begin{array}{l}\mathrm{APC}(95 \% \\
\mathrm{Cl}, \%)\end{array}$ & Year-range & $\begin{array}{l}\mathrm{APC}(95 \% \\
\mathrm{Cl}, \%)\end{array}$ & \\
\hline \multirow[t]{5}{*}{ Male } & $\begin{array}{l}\text { Malignant } \\
\text { Tumor }\end{array}$ & $2000-2007$ & $\begin{array}{l}1.8 \\
(0.2 \sim 3.4) *\end{array}$ & $2007-2017$ & $\begin{array}{l}-0.5 \\
(-1.4 \sim 0.4)\end{array}$ & $\begin{array}{l}0.4 \\
(-0.1 \sim 0.9)\end{array}$ \\
\hline & $\begin{array}{l}\text { Cerebrovascular } \\
\text { Disease }\end{array}$ & $2000-2002$ & $\begin{array}{l}-8.4 \\
(-21.7 \sim 7.2)\end{array}$ & $2002-2017$ & $\begin{array}{l}0.8 \\
(0.1 \sim 1.5)\end{array}$ & $\begin{array}{l}0.3 \\
(-0.3 \sim 1.0)\end{array}$ \\
\hline & Heart Trouble & $2000-2002$ & $\begin{array}{l}-7.1 \\
(-25.2 \sim 15.3)\end{array}$ & 2002 2017 & $\begin{array}{l}2.7 \\
(1.8 \sim 3.6)\end{array}$ & $\begin{array}{l}2.2 \\
(1.4 \sim 3.0)\end{array}$ \\
\hline & $\begin{array}{l}\text { Respiratory } \\
\text { Disease }\end{array}$ & 2000 2010 & $\begin{array}{l}-1.9 \\
(-3.7 \sim-0.1) \text { * }\end{array}$ & 2010 2017 & $\begin{array}{l}0.1 \\
(-3.0 \sim 3.3)\end{array}$ & $\begin{array}{l}-1.1 \\
(-1.9 \sim-0.4)\end{array}$ \\
\hline & $\begin{array}{l}\text { Trauma and } \\
\text { Toxicosis }\end{array}$ & 2000 2017 & $\begin{array}{l}-0.5 \\
(-1.7 \sim 0.7)\end{array}$ & $\sim$ & $\sim$ & $\begin{array}{l}-0.5 \\
(-1.7 \sim 0.7)\end{array}$ \\
\hline \multirow[t]{5}{*}{ Female } & $\begin{array}{l}\text { Malignant } \\
\text { Tumor }\end{array}$ & $2000-2017$ & $0.7(0.1-1.3)$ & $\sim$ & $\sim$ & $\begin{array}{l}0.7(0.1- \\
1.3) *\end{array}$ \\
\hline & $\begin{array}{l}\text { Cerebrovascular } \\
\text { Disease }\end{array}$ & $2000-2002$ & $\begin{array}{l}-5.7 \\
(-17 \sim 7.2)\end{array}$ & 2002 2017 & $\begin{array}{l}0.8 \\
(0.2 \sim 1.3)\end{array}$ & $\begin{array}{l}0.4 \\
(-0.1 \sim 0.9)\end{array}$ \\
\hline & Heart Trouble & 2000 2002 & $\begin{array}{l}-6.7 \\
(-28.9 \sim 22.4)\end{array}$ & 2002 2017 & $\begin{array}{l}3.2 \\
(2.1 \sim 4.4)\end{array}$ & $\begin{array}{l}2.7 \\
(1.8 \sim 3.6)\end{array}$ \\
\hline & $\begin{array}{l}\text { Respiratory } \\
\text { Disease }\end{array}$ & 2000 2009 & $\begin{array}{l}-3.8 \\
(-6.1 \sim-1.5) \text { * }\end{array}$ & $2009-2017$ & $\begin{array}{l}0.3 \\
(-2.5 \sim 3.2)\end{array}$ & $\begin{array}{l}-1.9 \\
(-2.9 \sim-1.0)\end{array}$ \\
\hline & $\begin{array}{l}\text { Trauma and } \\
\text { Toxicosis }\end{array}$ & 2000 2002 & $\begin{array}{l}9.4 \\
(-20.8 \sim 51.0)\end{array}$ & 2002 2017 & $\begin{array}{l}-1.6 \\
(-2.9 \sim-0.3)\end{array}$ & $\begin{array}{l}-1.1 \\
(-2.3 \sim 0.2)\end{array}$ \\
\hline \multirow[t]{3}{*}{ All } & $\begin{array}{l}\text { Malignant } \\
\text { Tumor }\end{array}$ & $2000-2008$ & ${ }_{*}^{1.7}(0.1-3.4)$ & $2008-2017$ & $\begin{array}{l}-0.5 \\
(-1.8 \sim 0.9)\end{array}$ & $\begin{array}{l}0.5 \\
(0.1 \sim 1.0)\end{array}$ \\
\hline & $\begin{array}{l}\text { Cerebrovascular } \\
\text { Disease }\end{array}$ & 2000-2002 & $\begin{array}{l}-6.6 \\
(-19.0 \sim 7.7)\end{array}$ & 2002 2017 & $\begin{array}{l}0.7 \\
(0.1 \sim 1.3)\end{array}$ & $\begin{array}{l}0.3 \\
(-0.2 \sim 0.9)\end{array}$ \\
\hline & Heart Trouble & 2000 2002 & $\begin{array}{l}-6.7 \\
(-24.3 \sim 15)\end{array}$ & 2002 2017 & $\begin{array}{l}2.9 \\
(2.0 \sim 3.8)\end{array}$ & $\begin{array}{l}2.4 \\
* \\
*\end{array}$ \\
\hline
\end{tabular}




\begin{tabular}{|c|c|c|c|c|c|c|}
\hline \multirow[t]{2}{*}{ Gender } & \multirow[t]{2}{*}{ Diseases } & \multicolumn{2}{|l|}{ Trends (1) } & \multicolumn{2}{|l|}{ Trends (2) } & \multirow{2}{*}{$\begin{array}{l}\text { AAPC } \\
(95 \% \mathrm{Cl}, \\
\%)\end{array}$} \\
\hline & & Year-range & $\begin{array}{l}\mathrm{APC}(95 \% \\
\mathrm{Cl}, \%)\end{array}$ & Year-range & $\begin{array}{l}\mathrm{APC}(95 \% \\
\mathrm{Cl}, \%)\end{array}$ & \\
\hline & $\begin{array}{l}\text { Respiratory } \\
\text { Disease }\end{array}$ & 2000 2010 & $\begin{array}{l}-2.4 \\
(-4.1 \sim-0.7)\end{array}$ & 2010 2017 & $\begin{array}{l}0.2 \\
(-2.8 \sim 3.3)\end{array}$ & $\begin{array}{l}-1.4 \\
(-2.2 \sim-0.7)\end{array}$ \\
\hline & $\begin{array}{l}\text { Trauma and } \\
\text { Toxicosis }\end{array}$ & $2000 \sim 2002$ & $\begin{array}{l}8.2 \\
(-21.6 \sim 49.3)\end{array}$ & 2002 2017 & $\begin{array}{l}-1.2 \\
(-2.5 \sim 0.2)\end{array}$ & $\begin{array}{l}-0.7 \\
(-1.9 \sim 0.5)\end{array}$ \\
\hline
\end{tabular}

In rural areas (Table 2, Online Supplementary Figure s2), the trends of the proportions of the top 5 causes of death are all significant except trauma and toxicosis in overall from 2000 to 2017. The AAPC of malignant tumor, cerebrovascular disease, heart trouble, and respiratory disease are $1.7 \%, 1.5 \%, 4.3 \%$, and $-3.6 \%$, respectively $(P<0.05)$. Stratification analysis by gender reveals that the AAPC of the proportion of deaths caused by respiratory disease from 2000 to 2017, lies entirely within a single joinpoint segment, with a declining trend and AAPC $=-3.3 \%$ in males (Online Supplementary Figure s2-D1), AAPC $=-4.0 \%$ in females (Online Supplementary Figure s2-D2), respectively $(P<0.05)$. Meanwhile, the declining trend of the proportions of deaths of trauma and toxicosis is significant only in females with AAPC $=-2.5 \%(P<0.05)$. 
Table 2

The trends of the top 5 causes of death in rural areas of China from 2000 to 2017

\begin{tabular}{|c|c|c|c|c|c|c|}
\hline \multirow[t]{2}{*}{ Gender } & \multirow[t]{2}{*}{ Diseases } & \multicolumn{2}{|l|}{ Trends (1) } & \multicolumn{2}{|l|}{ Trends (2) } & \multirow{2}{*}{$\begin{array}{l}\text { AAPC } \\
(95 \% \mathrm{Cl}, \\
\%)\end{array}$} \\
\hline & & Year-range & $\begin{array}{l}\mathrm{APC}(95 \% \\
\mathrm{Cl}, \%)\end{array}$ & Year-range & $\begin{array}{l}\mathrm{APC}(95 \% \\
\mathrm{Cl}, \%)\end{array}$ & \\
\hline \multirow[t]{5}{*}{ Male } & $\begin{array}{l}\text { Malignant } \\
\text { Tumor }\end{array}$ & 2000 2007 & $\begin{array}{l}4.5 \\
(2.5 \sim 6.6) \text { * }\end{array}$ & 2007 2017 & $\begin{array}{l}-1.1 \\
(-2.2 \sim 0.1)\end{array}$ & $\begin{array}{l}1.0 \\
(0.2 \sim 1.8)\end{array}$ \\
\hline & $\begin{array}{l}\text { Cerebrovascular } \\
\text { Disease }\end{array}$ & 2000 2017 & $\begin{array}{l}1.4 \\
(0.7 \sim 2.2)\end{array}$ & $\sim$ & $\sim$ & $\begin{array}{l}1.4 \\
(0.7 \sim 2.2)\end{array}$ \\
\hline & Heart Trouble & 2000 2005 & $\begin{array}{l}0.1 \\
(-5.3 \sim 5.8)\end{array}$ & 2005 2017 & $\begin{array}{l}5.0 \\
(3.5 \sim 6.6) \\
*\end{array}$ & $\begin{array}{l}3.9 \\
(2.9 \sim 4.9)\end{array}$ \\
\hline & $\begin{array}{l}\text { Respiratory } \\
\text { Disease }\end{array}$ & 2000 2017 & $\begin{array}{l}-3.3 \\
(-4.5 \sim-2.2) \text { * }\end{array}$ & $\sim$ & $\sim$ & $\begin{array}{l}-3.3 \\
(-4.5 \sim-2.2)\end{array}$ \\
\hline & $\begin{array}{l}\text { Trauma and } \\
\text { Toxicosis }\end{array}$ & 2000 2017 & $\begin{array}{l}-0.6 \\
(-1.6 \sim 0.4)\end{array}$ & $\sim$ & $\sim$ & $\begin{array}{l}-0.6 \\
(-1.6 \sim 0.4)\end{array}$ \\
\hline \multirow[t]{5}{*}{ Female } & $\begin{array}{l}\text { Malignant } \\
\text { Tumor }\end{array}$ & 2000 2017 & $\begin{array}{l}1.0 \\
(-0.1 \sim 2.0)\end{array}$ & $\sim$ & $\sim$ & $\begin{array}{l}1.0 \\
(-0.1 \sim 2.0)\end{array}$ \\
\hline & $\begin{array}{l}\text { Cerebrovascular } \\
\text { Disease }\end{array}$ & 2000 2003 & $\begin{array}{l}10.7 \\
(0.9 \sim 21.4)\end{array}$ & 2003 2017 & $\begin{array}{l}1.2 \\
(0.3 \sim 2.1)\end{array}$ & $\begin{array}{l}2.8 \\
(1.2 \sim 4.5)\end{array}$ \\
\hline & Heart Trouble & 2000 2005 & $\begin{array}{l}0.7 \\
(-4.4 \sim 6.1)\end{array}$ & $2005 \sim 2017$ & $\begin{array}{l}5.1 \\
(3.7 \sim 6.6) \\
*\end{array}$ & $\begin{array}{l}4.1 \\
(3.2 \sim 5.0)\end{array}$ \\
\hline & $\begin{array}{l}\text { Respiratory } \\
\text { Disease }\end{array}$ & 2000 2017 & $\begin{array}{l}-4.0 \\
(-5.3 \sim-2.8) \text { * }\end{array}$ & $\sim$ & $\sim$ & $\begin{array}{l}-4.0 \\
(-5.3 \sim-2.8) \\
\star\end{array}$ \\
\hline & $\begin{array}{l}\text { Trauma and } \\
\text { Toxicosis }\end{array}$ & 2000 2003 & $\begin{array}{l}-13.7 \\
(-22.9 \sim-3.4) \\
\star\end{array}$ & 2003 2017 & $\begin{array}{l}0.1 \\
(-1.0 \sim 1.1)\end{array}$ & $\begin{array}{l}-2.5 \\
(-4.4 \sim-0.6) \\
\star\end{array}$ \\
\hline \multirow[t]{3}{*}{ All } & $\begin{array}{l}\text { Malignant } \\
\text { Tumor }\end{array}$ & 2000 2003 & $\begin{array}{l}11.4(1.8- \\
21.9) *\end{array}$ & 2003 2017 & $\begin{array}{l}-0.3 \\
(-1.1 \sim 0.6)\end{array}$ & $\begin{array}{l}1.7 \\
(0.1 \sim 3.3)\end{array}$ \\
\hline & $\begin{array}{l}\text { Cerebrovascular } \\
\text { Disease }\end{array}$ & $2000-2017$ & $\begin{array}{l}1.5 \\
(0.6 \sim 2.5) \text { * }\end{array}$ & $\sim$ & $\sim$ & $\begin{array}{l}1.5 \\
(0.6 \sim 2.5)\end{array}$ \\
\hline & Heart Trouble & 2000 2005 & $\begin{array}{l}0.1 \\
(-4.3 \sim 4.7)\end{array}$ & 2005 2017 & $\begin{array}{l}5.5 \\
(4.3 \sim 6.8)\end{array}$ & $\begin{array}{l}4.3 \\
(3.4 \sim 5.2)\end{array}$ \\
\hline
\end{tabular}




\begin{tabular}{|c|c|c|c|c|c|c|}
\hline \multirow[t]{2}{*}{ Gender } & \multirow[t]{2}{*}{ Diseases } & \multicolumn{2}{|l|}{ Trends (1) } & \multicolumn{2}{|l|}{ Trends (2) } & \multirow{2}{*}{$\begin{array}{l}\text { AAPC } \\
(95 \% \mathrm{Cl}, \\
\%)\end{array}$} \\
\hline & & Year-range & $\begin{array}{l}\mathrm{APC}(95 \% \\
\mathrm{Cl}, \%)\end{array}$ & Year-range & $\begin{array}{l}\mathrm{APC}(95 \% \\
\mathrm{Cl}, \%)\end{array}$ & \\
\hline & $\begin{array}{l}\text { Respiratory } \\
\text { Disease }\end{array}$ & 2000 2017 & $\begin{array}{l}-3.6 \\
(-4.8 \sim-2.3) \text { * }\end{array}$ & $\sim$ & $\sim$ & $\begin{array}{l}-3.6 \\
(-4.8 \sim-2.3)\end{array}$ \\
\hline & $\begin{array}{l}\text { Trauma and } \\
\text { Toxicosis }\end{array}$ & 2000 2003 & $\begin{array}{l}-13.2 \\
(-23.1 \sim-2.1) \\
\star\end{array}$ & 2003 2017 & $\begin{array}{l}0.8 \\
(-0.3 \sim 1.9)\end{array}$ & $\begin{array}{l}-0.7 \\
(-2.1 \sim 0.8)\end{array}$ \\
\hline $\begin{array}{l}\text { APC: } A \\
\text { indica }\end{array}$ & Percent C & PC: Aver & nnual Pero & hange; $\mathrm{Cl}$ : & idence in & al; *: \\
\hline
\end{tabular}

The combined proportion of deaths due to cerebrovascular disease and heart trouble increases (39.0243.56\%, $P<0.05)$ from 2000 to 2017, which is higher than that due to malignant tumor in overall in urban areas $(P<0.05)$ (Figure 1-A1). The AAPC of the proportion of deaths of cardio-cerebrovascular disease from 2000 to 2017 lies within 2 joinpoint segments (AAPC=1.3\%, $P<0.05$ ), with an increasing trend from 2002 to 2017 and $\mathrm{APC}=1.74 \%(P<0.05)$, (Figure 1-A3), which is higher than that of malignant tumor (Figure 1). The results of stratification analysis by gender is similar. In rural areas, the proportion of deaths of cardio-cerebrovascular disease increases (32.03-45.91\%, $P<0.05)$ from 2000 to 2017 and is higher than that of malignant tumor in overall $(P<0.05)$ (Figure 2-A1). The AAPC of the proportion of deaths of cardio-cerebrovascular disease is $2.7 \%(P<0.05)$ (Figure 2-A3), with a peak in females at $3.04 \%$ $(P<0.05)$ (Figure 2-F3). Overall, the increasing trend of the proportions of deaths of cardio-cerebrovascular disease is steeper than that of malignant tumor, which is not related to gender (Figure 1,2).

\section{Discussion}

This study reveals that in China, the top 5 consistent causes of death are malignant tumor, cerebrovascular disease, heart trouble, respiratory disease, and trauma and toxicosis during the past 18 years. All these 5 causes account for $82.6 \%$ in $2000,86.49 \%$ in 2017 in urban areas and $83.31 \%$ in 2000 , $88.34 \%$ in 2017 in rural areas of the total deaths. Trend analysis results suggest that the proportions of death of malignant tumor, cerebrovascular disease, and heart trouble have significantly increased, while the one of respiratory disease has significantly decreased. The declining trend of the proportion of death of trauma and toxicosis is significant only in females. In addition, the increasing trend of the proportion of death of cardio-cerebrovascular disease is steeper than that of malignant tumor (AAPC: Urban, $1.5 \%$ vs $0.5 \%$; Rural, $2.7 \%$ vs $1.7 \%$ ), the decreasing trend of the proportion of respiratory disease in rural areas is steeper than that in urban areas (AAPC: $-3.6 \%$ vs $-1.4 \%$ ).

Malignant tumor is the first-leading cause of death in the world. The GLOBOCAN 2018 estimated that there were 18.1 million new cases of malignant tumor and 9.6 million related deaths in $2018^{7}$. The large burden of malignant tumor is projected to increase with a predicted 22 million new cases and 13 million related deaths occurring by $2030^{8}$. Previous studies have identified that the malignant tumor burden is 
greater in higher Human Development Index countries $^{9,10}$, while a greater proportion of the global mortality burden was observed in low and medium Human Development Index countries. The proportion of malignant tumor incidence will experience a $100 \%$ and $81 \%$ increase in low and medium Human Development Index countries from 2008 to 2030 , respectively ${ }^{11}$. Our study estimated that malignant tumor was the first-leading cause of death in China with AAPC=0.5\% and 1.7\% from 2000 to 2017 in urban and rural areas, respectively. Malignant tumor-related deaths were more popular in urban than in rural areas. Even the proportion of death caused by malignant tumor presented a continuing upward trend during the past 18 years, the one in urban areas only continuously increased from 2000 to 2008 . In urban areas, malignant tumor-related deaths accounted for $27.12 \%$ of total deaths in 2008 , and its proportion has been fluctuating at a high level from 2008 to 2017. In rural areas, even malignant tumorrelated deaths only accounted for $23.07 \%$ (lower than $25.50 \%$ ) of total deaths in 2017 , it presented a continuing upward trend from 2008 to 2017 . Based on this result, we urgently need to control its occurrence in rural areas in China, but at the same time, we should also strengthen interventions for urban populations because of their high base.

In 2016, it was reported that CVD accounted for more deaths than tumor or any other disease did in China, which was the first-leading cause of death in China ${ }^{12}$. In 2018, National Center for Cardiovascular Diseases estimated that about 290 million patients were suffered from CVD in China, including 13 million from stroke, 11 million from coronary heart disease, 5 million from pulmonary heart disease, 4.5 million from heart failure, 2.5 million from rheumatic heart disease, 2 million from congenital heart disease and 245 million from hypertension ${ }^{12}$. Our study indicated that the proportion of death caused by malignant tumor was higher than that caused by cerebrovascular disease and heart trouble, but lower than that caused by CVD. CVD-related deaths accounts for more than $40 \%$ of total deaths after 2010 , especially in females (more than $45 \%$ ), with a peak of $50.4 \%$ in rural females in 2017. Increasing aging, lifestyle changes, psychological stress, and other unhealthy behaviors have led to a continuous increase in the number of heart trouble ${ }^{13}$, increasing the burden of cardiovascular disease, especially the increase in cardiovascular mortality in rural areas in China. Note that the proportion of death of heart trouble is rising fastest, especially in rural areas with AAPC $=4.3 \%$. However, the density of health-care professionals is lower in rural than urban areas in China ${ }^{14}$. So, strengthening the prevention and treatment of CVD under the leadership of the government is an urgent task, both in urban and rural areas.

According to the Global Burden of Disease 2016 (GBD 2016) study, respiratory disease has become the 4th -leading cause of death globally, which has brought tremendous health burdens to society. The occurrence of respiratory diseases is closely related to economic development. With the development of economy and the acceleration of urbanization in China, the proportion of death caused by respiratory diseases is decreasing, especially in rural areas with AAPC $=-3.6 \%$ from 2000 to 2017. On the other hand, the occurrence of respiratory diseases is also closely related to air quality ${ }^{15}$, since China has experienced a severe deterioration in air quality over the past several years. Respiratory diseases-related deaths accounted for more than $11 \%$ of total death in 2017 , even though it has been on a decreasing trend. Trauma and toxicosis is a significant public health problem and among the leading causes of death 
worldwide $^{16}$. It was consistently the fifth leading cause of death in China from 2000 to 2017. Road traffic crashes ${ }^{16}$ and alcohol use ${ }^{17}$ are the leading risk factors for death and disability, particularly among males in China ${ }^{18}$, which contribute to health loss from many causes and exacted their toll throughout the rest of victims' lifetime. Fall injury is a serious cause of morbidity among older people and its occurrence increases dramatically with age ${ }^{19}$. China has begun the accelerated aging process. As a result, there will be more and more older people in the future, and fall injury will be an important cause of trauma and toxicosis-related death. Therefore, in order to prevent trauma and toxicosis, these interventions such as speed enforcement and drink-driving enforcement need to be strengthened ${ }^{20}$.

There might be several limitations in our study. First, the reprocessing of secondary data cannot be further adjusted nor standardized in this study. Our results are not based on the original data although the data we used came from a wide range of years from 2000 to 2017. Second, we did not analyze the determinants of the causes of death since our study is an exploratory ecological trend study. Third, the results of our study can only give the weight of different causes of death and reflect the trend of proportion since this study is based on the composition of the causes of death rather than mortality.

In conclusion, the top 5 causes of death in China account for more than $85 \%$ of all deaths in 2017 . The trends of all diseases have been increasing, except for respiratory disease. Cardio-cerebrovascular disease should be the primary focus for disease prevention and control since it has accounted for the largest proportion with the steepest increasing trend during the past 18 years.

\section{Declarations}

Funding: This study was supported by the National Natural Science Foundation of China (grant no. 82103935).

Conflicts of interest: The authors declare no conflicts of interest.

Data Availability Statement: The data that support the findings of this study are openly available in National Bureau of Statistics at http://www.stats.gov.cn/tjsj/ndsj/.

Author's Contributions $\square$ Yongcheng Ren substantially contributed to the design and drafting of the study and the analysis and interpretation of the data. Haiyin Zou revised it critically for important intellectual content. All authors were involved in collecting data and approved the final version of the manuscript.

\section{Acknowledgments}

This study was supported by the National Natural Science Foundation of China (grant no. 82103935) and Young Key Teacher Funding Program of Huanghuai Univeristy.

\section{Duality of interest}

All authors declare no conflict of interest related to this study. 


\section{Ethical approval}

This article does not contain any studies with human participants or animals performed by any of the authors.

\section{References}

1. WHO. The top 10 causes of death., 2018.

2. WHO. Global Health Observatory (GHO) data., 2019.

3. Yang G, Hu J, Rao KQ, Ma J, Rao C, Lopez AD. Mortality registration and surveillance in China: History, current situation and challenges. Popul Health Metr 2005;3(1):3.

4. Center PHSD. National Disease Surveillance System-Death Cause Monitoring Network Report Database. Vol. 2019, 2019.

5. China NBOS. China Statistical Yearbooks. Beijing: China statistical Publishing House, 2001.

6. Kim HJ, Fay MP, Feuer EJ, Midthune DN. Permutation tests for joinpoint regression with applications to cancer rates. Stat Med 2000;19(3):335-51.

7. Bray F, Ferlay J, Soerjomataram I, Siegel RL, Torre LA, Jemal A. Global cancer statistics 2018: GLOBOCAN estimates of incidence and mortality worldwide for 36 cancers in 185 countries. CA Cancer J Clin 2018;68(6):394-424.

8. Ferlay J, Soerjomataram I, Dikshit R, Eser S, Mathers C, Rebelo M, Parkin DM, Forman D, Bray F. Cancer incidence and mortality worldwide: sources, methods and major patterns in GLOBOCAN 2012. Int J Cancer 2015;136(5):E359-86.

9. Fidler MM, Soerjomataram I, Bray F. A global view on cancer incidence and national levels of the human development index. Int J Cancer 2016;139(11):2436-46.

10. Bray F, Jemal A, Grey N, Ferlay J, Forman D. Global cancer transitions according to the Human Development Index (2008-2030): a population-based study. Lancet Oncol 2012;13(8):790-801.

11. Fidler MM, Bray F, Soerjomataram I. The global cancer burden and human development: A review. Scand J Public Health 2018;46(1):27-36.

12. Hu S, Gao R, Liu L, Zhu M, Wang W, Wang Y, Wu Z, Li H, Gu D, Yang Y, Zheng Z, Chen W. Summary of the 2018 Report on Cardiovascular Diseases in China. Chinese Circulation Journal 2019; 34(3):209-220

13. Li Y, Zeng X, Liu J, Liu Y, Liu S, Yin P, Qi J, Zhao Z, Yu S, Hu Y, He G, Lopez AD, Gao GF, Wang L, Zhou $M$. Can China achieve a one-third reduction in premature mortality from non-communicable diseases by 2030? BMC Med 2017;15(1):132. 
14. Anand S, Fan VY, Zhang J, Zhang L, Ke Y, Dong Z, Chen LC. China's human resources for health: quantity, quality, and distribution. Lancet 2008;372(9651):1774-81.

15. Luo L, Zhang Y, Jiang J, Luan H, Yu C, Nan P, Luo B, You M. Short-Term Effects of Ambient Air Pollution on Hospitalization for Respiratory Disease in Taiyuan, China: A Time-Series Analysis. Int $J$ Environ Res Public Health 2018;15(10).

16. Korhonen N, Niemi S, Parkkari J, Palvanen M, Kannus P. Unintentional injury deaths among adult Finns in 1971-2008. Injury 2011;42(9):885-8.

17. Alcohol use and burden for 195 countries and territories, 1990-2016: a systematic analysis for the Global Burden of Disease Study 2016. Lancet 2018;392(10152):1015-1035.

18. Yang G, Zhang F, Ji L. 2013. Drink driving in the background of public health. Chinese Journal of Health Education 2013;(8):735-737.

19. Korhonen N, Kannus P, Niemi S, Palvanen M, Parkkari J. Fall-induced deaths among older adults: nationwide statistics in Finland between 1971 and 2009 and prediction for the future. Injury 2013;44(6):867-71.

20. Vecino-Ortiz Al, Jafri A, Hyder AA. Effective interventions for unintentional injuries: a systematic review and mortality impact assessment among the poorest billion. Lancet Glob Health 2018;6(5):e523e534.

\section{Figures}

\section{Figure 1}

Comparison of trends for malignant tumor and cardio-cerebrovascular disease as causes of death in urban areas of China from 2000 to 2017.

Note: A: all; M: male; F: female; 1: line chart based on raw data; 2: Joinpoints graph for malignant tumor; 3: Joinpoints graph for cardio-cerebrovascular disease; APC: Annual Percent Change; AAPC: Average Annual Percent Change; *: indicates that AAPC or APC is significantly different from zero at the alpha $=0.05$ level.

\section{Figure 2}


Comparison of trends for malignant tumor and cardio-cerebrovascular disease as causes of death in rural areas of China from 2000 to 2017.

Note: A: all; M: male; F: female; 1: line chart based on raw data; 2 : Joinpoints graph for malignant tumor; 3: Joinpoints graph for cardio-cerebrovascular disease; APC: Annual Percent Change; AAPC: Average Annual Percent Change; *: indicates that AAPC or APC is significantly different from zero at the alpha $=0.05$ level.

\section{Supplementary Files}

This is a list of supplementary files associated with this preprint. Click to download.

- OnlineSupplementaryFigures1.pdf

- OnlineSupplementaryFigures2.pdf 